which they were most conversant. The Senate favoured the scheme, and Sir Walter Palmer, by a timely gift of $2000 l$., rendered available the space which the Senate had assigned for the laboratory. The University supported the scheme with a grant of $500 l$, and has since provided an annual grant of $400 l$. for five years, conditional upon the acquisition of $600 l$, per annum from other sources. Upon this annual subsidy of roool., it is estimated that the present activity of the laboratory can be sustained. So far the support obtained from outside sources, the $3000 l$. required for the five years, 1904-1909, is represented by $2000 l$. subscribed by Mr. G. W. Palmer and Mr. A. Palmer. The sum asked for has therefore not yet been collected; when collected, it should be noted, it will not serve to maintain the laboratory upon a scale commensurate with its activity and promise. Thus the estimated expenditure of Ioool. per annum includes no provision for the honoraria of lecturers, or for additional assistants, or for research scholarships. The sum of $50,000 l$, it is estimated, would suffice for the accomplishment of this greater object.

\section{THE MONTE ROSA AND COL D'OLEN} INTERNATIONAL LABORATORIES.

SOME time ago (Nature, April I7, I902, vol. 1xv. p. 568) I directed the attention of the readers of NATURE to the international laboratory, the Capanna Regina Margherita, which had been established on the Gnifetti peak of Monte Rosa by Prof. Mosso, of Turin, through the generous aid of the Regina Madre of Italy. Already much valuable work has been done in that laboratory, and if this has been chiefly of a physiological kind, though provision is made in the laboratory for physical and meteorological as well as other investigations, the reason is to be sought partly in the fact that Prof. Mosso is a physiologist, partly in the special interest attaching to the physiological problems presented by living beings at high altitudes.

In August and September, I903, two physiological expeditions were carried out at the Capanna Regina Margherita, one under the direction of Prof. Zuntz, of Berlin; the other by Prof. Mosso, several observers taking part in each. The records of some of (not of all) the results obtained in these two expeditions are now brought together by Prof. Mosso in a volume? of some 300 pages, elegantly bound in such a way as to be easily itself carried to high altitudes, and appropriately dedicated to that Mæcenas of science M. Ernest Solvay, who has so freely given back to science of the good things which science has given to him.

I do not propose, in this notice, to deal in detail with the twenty-one memoirs which make up the volume. One, that by Durig and Zuntz, is given in German; all the others, though written by Italian observers, with that generous abnegation of their own tongue which it is to be hoped will not be considered necessary for them in the coming years, appear in French. I may here perhaps be allowed to express my regret that no memoir by any English observer, either in his own or any other language, is to be found among them. All of them treat, more or less directly, with one or other of the many problems of metabolism which are presented by life at such a high altitude as 4560 metres. At that height the responses which internal chemical, metabolic, processes and the expenditure of energy make to changes in the en-

1 Laboratoire Scientifique Internatinral du Monte Rosa. Travaux de l'année 1903. Publiés par A. Mosso. (Turin: Loescher, 1904.)

No. 1845 , vor. 7 I] vironment are so different from those which take place at lower levels as to raise great hopes that persistent researches in such Alpine laboratories may carry us far towards solving the intricate problems of the relation of chemical and physical changes of living substance to the energies of life. It may be added that such researches may be expected to explain, and so to afford practical guidance as to, the beneficial sanitary effects of life at high altitudes on many diseases.

Most of the memoirs, as might be expected, record studies on the respiratory exchange and on the condition of the blood at the high altitude as compared with what is found at an ordinary low level; and in some of them the effects of artificially lowering barometric pressure at Turin are compared with the effects of the natural low pressure on Monte Rosa, accompanied as the latter is with other conditions. All these are of great interest to the physiologist, and to him chiefly; but one memoir may perhaps attract the attention of the general reader, and that is the one by Mosso and Galeotti on the physiological effects of alcohol at high altitudes. These observers found that a dose of alcohol, 40 c.c. of absolute alcohol adequately diluted, which at Turin brought about a condition bordering on drunkenness produced, on Monte Rosa, so far as subjective sensations were concerned, hardly any effect at all. I may add that the present volume does not record all the observations made in the expeditions of 1903 , a second volume being about to appear shortly. Nor are physiological researches the only ones which have been carried out; important meteorological and physical inquiries have also been conducted.

In spite of every effort to make the accommodation at the Gnifetti laboratory as complete as possible in the circumstances, those circumstances offer many obstacles to continued successful observations. The period during which study is possible is short, and the hardships of living and working at such a high altitude are such as cannot easily be borne by many persons otherwise capable of carrying out fruitful investigations. Hence Prof. Mosso conceived the idea of establishing in connection with the Gnifetti laboratory a supplementary laboratory at a lower but still high level, where work could be carried on in connection with the higher laboratory, but under easier conditions, and for a longer period of the year.

Visitors to the southern slopes of the Monte Rosa group probably know well the little wooden inn at the Col d'Olen at the height of about 3000 metres, reached by a long but easy walk or mule ride from Alagna, and most admirably kept by the well known enterprising hotel proprietors Guglielmina. From it one may, when the air is clear, see afar off the Duomo of Milan, while at one's feet alongside the path to Gressonay lies an Alpine garden which Kew may envy, brilliant in late summer with sheets of gentian and other lovely flowers. Close by the inn, Prof. Mosso has secured a plot of ground on which he is building the new laboratory; this he hopes to have finished next autumn, but it will not be ready for actual use until the summer of 1906.

It is to be a laboratory fully equipped for researches in physiology, meteorology, physics, and botany; but in addition to this it will have sixteen comfortable bedrooms, so that sixteen workers carrying on investigations will have each a bedroom to himself; and if the number of observers should happen at any time to exceed sixteen, accommodation can be obtained at the inn close by. At such altitudes success in investigation is largely dependent on personal comfort, including suitable food; and probably there are not a 
few to whom research at the high Gnifetti laboratory would be impossible, but who could do solid work at a somewhat lower level provided that the life was not too rough, and especially if they had no fear of being hampered by indigestion caused by too rude or monotonous a diet. For these especially is the Col d'Olen Laboratory intended; and unless things have altered sadly in the last few years, such need have no fear for their stomachs. I still have a vivid recollection of a stay at the inn at $\mathrm{Col}$ d'Olen during which the efforts of a talented cook produced results which would have satisfied tastes of a far higher epicurean level than my own.

The new laboratory, like the old, is to be carried out as an international institution. It received warm support from the International Physiological Congress at Turin in I9OI, and again at Brussels this year. After the plan of the Stazione Zoologica at Naples, its maintenance is to be provided by subsidies which will give the right to occupy working places. Already the Italian Ministry of Instruction has secured accom- be on a safe basis, and especially that an annual income should be provided sufficient to ensure at the laboratory adequate service and assistance, which, as might be expected from the circumstances, have to be well paid. The existence of such a laboratory offers unusual opportunities for investigation, not only to those who are interested in the general problems of physiology, of meteorology, and of the physics of the earth, but also to the perhaps larger class who desire a wider and more exact knowledge of the manifold fascinating phenomena of the High Alps. Is it too much to hope that Prof. Mosso will find no great difficulty in obtaining the further funds which he needs?

M. Foster.

\section{NEOLITHIC DEPOSITS IN THE NORTH-EAST $O F$ IRELAND}

$T H E$ recent changes of level in the north-east of Ireland attracted a considerable amount of public interest during the year 1903, in consequence of the

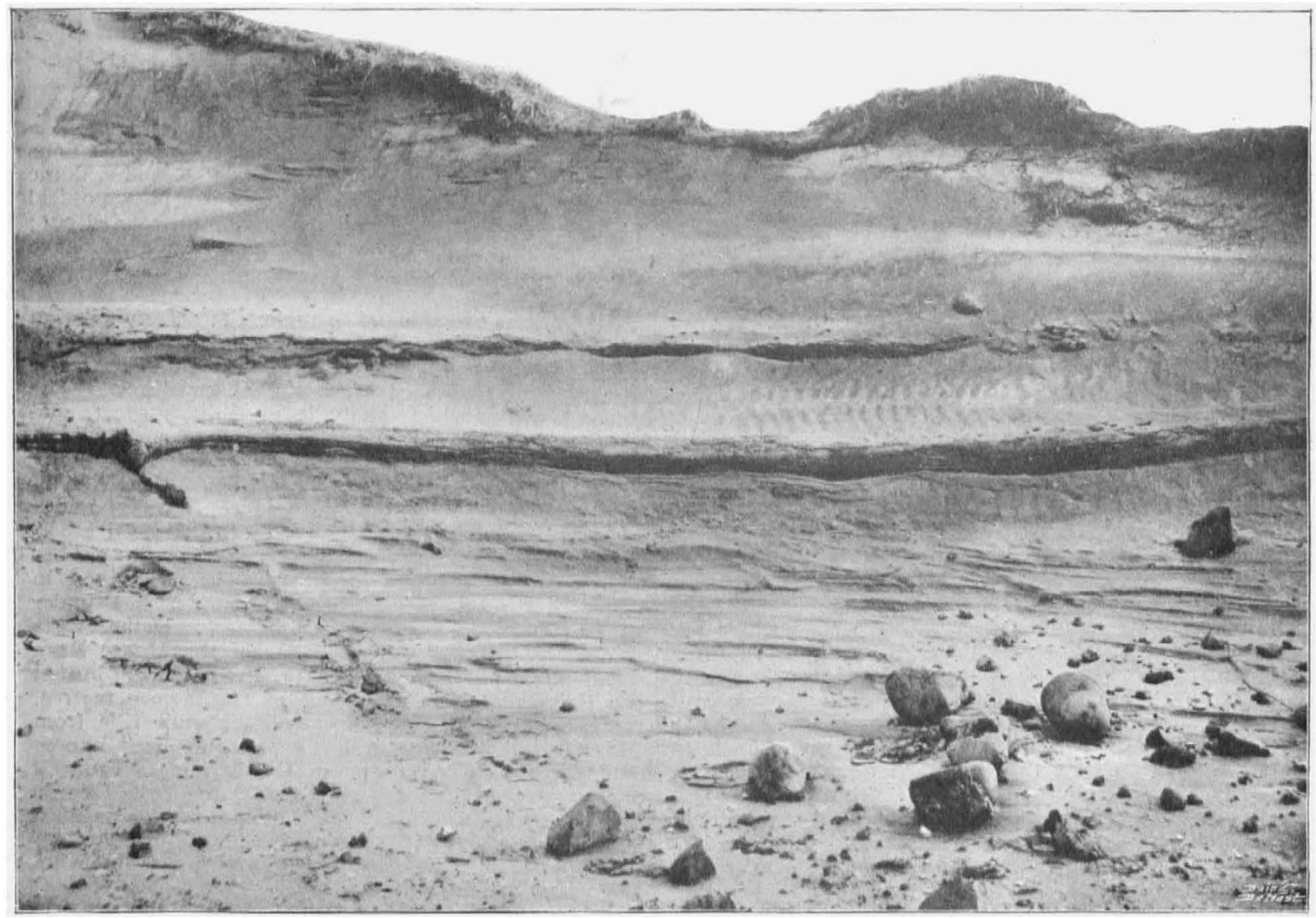

Fig. r.-Wind excavated Pit in Portstewart Sand.dunes, showing "black-layers." From Proceedings of the Royal Irish Academy, December, Ig04.

modation for two investigators, the Italian Alpine Club for one, and the German Government for two. M. Solvay, who has otherwise been a lavish benefactor to the whole enterprise, has taken two places for Belgium, and, through the generosity of Dr. Ludwig Mond, our own Royal Society has the right of nominating two investigators. The undertaking, therefore, is well on the way to success; but much remains yet to be done. Prof. Mosso informs me that though he has obtained 70,000 lire, he still needs some 50,000 lire in order that everything should lawsuit, known as the "Gold Ornaments Case" (Attorney-General v. the Trustees of the British Museum). A golden boat, collar, and other objects were found in ploughing at Broighter, on the extensive flat that stretches around Limavady Junction in county Londonderry. They were buried eighteen inches deep in stiff clay soil, at a spot which is four feet above ordinary high-water mark. The British Museum authorities rested their claim to the retention of the objects in part on the theory that the ornaments in question constituted a votive offering, which was 